\title{
Doctors' attitudes, medical philosophy, and political views
}

\author{
RICHARD E WAKEFORD, LYNNE ALLERY
}

In 1981 Harris illustrated the existence of medical specialty stereotypes in the minds of medical students. ${ }^{1}$ For example, on starting and when leaving the medical course students categorised surgeons as "domineering and arrogant" and psychiatrists as "emotionally unstable."

Such persistent stereotypes may well play a part in specialty choice, a subject on which we are conducting research. But are the stereotypes reflected-and thus possibly generated-by differences in attitudes and orientations exhibited by doctors in different specialties? To examine this question, we undertook a study of the attitudes of selected groups of doctors towards some current moral and practice issues. Some of these were known to be controversial among doctors, and thus should show differences between specialties if such exist. We also asked doctors about their political orientation and philosophy of medical practice.

\section{Method}

A questionnaire was developed and pilot tested with the aid of local medical colleagues. It comprised 12 attitude items, and to each of these respondents were invited to tick one of: "agree"; "tend to agree"; "no opinion/mixed feelings/don't know"; "tend to disagree"; or "disagree." Five of these items related to medicomoral matters, such as surrogate motherhood, six related to practice issues-for example, the desirability of a limited list of drugs in general practice-and one was an attitude item used in a previous study to discriminate between doctors with a humanistic medical philosophy and those with a technological one. ${ }^{\text {la }}$ The questionnaire finally asked the respondent to give his or her specialty, to indicate his age, and, to set his views in context, to classify his political outlook. It took the form of a sheet of card, perforated vertically down the centre, with the questions on the left and the response spaces on the right. On completion the side containing the responses was detached and then formed a reply paid postcard.

Three main samples of potential respondents were drawn from pages of the Medical Directory. Using random number tables to select the pages, the first doctor listed in each of the following three categories was picked: $(a)$ consultant physicians (including medical subspecialties); (b) consultant surgeons (including surgical subspecialties); and (c) identifiable general practitioners, or those with no stated specialisation-in this case, that they were general practitioners was checked by reference to local family practitioner committee lists.

Cambridge University School of Clinical Medicine, Cambridge CB2 2 QQ RICHARD E WAKEFORD, MA, senior research associate LYNNE ALLERY, MA, research assistant

Correspondence to: $\mathrm{Mr}$ Wakeford, Clinical School Offices, Addenbrooke's Hospital, Hills Road, Cambridge CB2 2QQ.
The size of each of these samples was 200 .

In addition and by a similar method two further, smaller samples of 75 doctors each were drawn from $(d)$ those listed as consultant psychiatrists (this to relate to earlier work undertaken on this specialty); and (e) women doctors in any specialty, or none (this to gain an indication of the views of an important group of doctors who would inevitably form a small proportion of the other samples).

Doctors with foreign or evident accommodation addresses were excluded. To make the sample representative of established, working senior doctors, only those who qualified between 1943 and 1972 were included.

The questionnaire was mailed with a covering letter on 18 February 1985 . To encourage responses from doctors who might be away-for example, on holiday - no return date was indicated. No follow up was attempted because of the anonymous nature of the study. Analysis took place after two months: the $\chi^{2}$ test was used for the analysis of categorical and ordinal data with a confidence level of $2 \%$.

\section{Results}

Five hundred and seven completed questionnaires were returned. Ten further ones were returned marked "dead" (two), "gone away" (six), or "not applicable-retired" (two). Excluding these, the overall response rate from living, practising, locatable doctors was an acceptable $69 \%$. This did not vary markedly between the groups of doctors.

Table I shows the doctors' responses to the six items relating to practice issues. There were no important differences between groups on four of the items-those concerning contingency planning for the acquired immune deficiency syndrome (AIDS), the adequacy of doctors' training in communication skills, transfer of patient care to the community, and the efficacy of the National Health Service as a system of medical care. Differences in response to the limited list item arose out of a somewhat lower enthusiasm for the proposal from the general practitioners compared with hospital doctors, but each specialty group was at least three to one in favour. The significant difference on the final item-whether being a doctor was a rewarding occupation-was accounted for by a slightly less fulsome agreement with the proposition from the general practitioners and psychiatrists. (In this and the other tables percentages are rounded off.)

Responses to the moral issues are presented in table II. On only one of these were there significant differences between the groups of doctors - on the justification for the loss of animal life in pharmaceutical research. Surgeons were strongest in support, while general practitioners, psychiatrists, and women doctors were less firm in their views-but each group, overall, strongly supported this proposition.

A comparison of the medical philosophy of the groups of respondents is given in table III. Here, the percentages of each group giving the most extreme responses, "agree" or "disagree," to the attitude item "Scientific advances in medicine have led to a dehumanised attitude by some doctors towards patients" is given as an indication of this. Surgeons were the most firmly technological, 
TABLE I-Responses to practice issues. (Values are numbers (\%) of responses)

\begin{tabular}{|c|c|c|c|c|c|}
\hline Statement & Agree & $\begin{array}{l}\text { Tend to } \\
\text { agree }\end{array}$ & $\begin{array}{l}\text { No opinion/mixed feelings/ } \\
\text { don't know }\end{array}$ & $\begin{array}{l}\text { Tend to } \\
\text { disagree }\end{array}$ & Disagree \\
\hline $\begin{array}{l}\text { Some form of limited list of drugs in general practice is desirable (not necessarily the list presently being } \\
\text { proposed) }\end{array}$ & $294(58)$ & $119(23)$ & $11(2)$ & $34(7)$ & $49(10)$ \\
\hline $\begin{array}{l}\text { Urgent contingency planning should be undertaken at local levels to contain a possible widespread } \\
\text { outbreak of AIDS }\end{array}$ & $129(25)$ & $106(21)$ & $104(21)$ & $93(18)$ & $75(15)$ \\
\hline Medical students and doctors are not sufficiently trained in the skills of doctor-patient communication & $219(43)$ & $147(29)$ & $41(8)$ & $71(14)$ & $29(6)$ \\
\hline
\end{tabular}

Significant differences between groups of doctors (specialties): ${ }^{\star} \chi^{2}=18 \cdot 35, \mathrm{df}=8, \mathrm{p}<0 \cdot 02 ; \star \star \chi^{2}=20 \cdot 19, \mathrm{df}=4, \mathrm{p}<0 \cdot 001$ (combining columns in each case)

TABLE II-Responses to moral issues. (Values are numbers (\%) of responses)

\begin{tabular}{|c|c|c|c|c|c|}
\hline Statement & Agree & $\begin{array}{l}\text { Tend to } \\
\text { agree }\end{array}$ & $\begin{array}{c}\text { No opinion/mixed feelings/ } \\
\text { don't know }\end{array}$ & $\begin{array}{l}\text { Tend to } \\
\text { disagree }\end{array}$ & Disagree \\
\hline $\begin{array}{l}\text { All research on human embryos should be forbidden } \\
\text { General practitioners should be legally free to provide contraceptive advice and contraceptives to under } 16 \mathrm{~s}\end{array}$ & $82(16)$ & $58(11)$ & $52(10)$ & $120(24)$ & $195(39)$ \\
\hline without parental consent & $203(40)$ & $83(16)$ & $33(7)$ & $65(13)$ & $123(24)$ \\
\hline Tobacco sponsorship of any sport should be banned & $272(54)$ & $69(14)$ & $40(8)$ & $51(10)$ & $75(15)$ \\
\hline Some loss of animal life is justified in the development of new pharmaceutical products for mankind & $364(72)$ & $109(21)$ & $18(4)$ & $8(2)$ & $8(2)$ \\
\hline In some situations surrogate motherhood is quite acceptable & $140(28)$ & $103(20)$ & $65(13)$ & $82(16)$ & $117(23)$ \\
\hline
\end{tabular}

*Significant difference between groups of doctors: $\chi^{2}=24 \cdot 46, \mathrm{df}=8$ (combining columns), $\mathrm{p}<0 \cdot 01$.

TABLE III-Indication of "medical philosophy" of groups of doctors. (Values are numbers (\%) of responses)

\begin{tabular}{lcc}
\hline \multicolumn{1}{c}{ Category of doctor } & Firmly “technological" & Firmly "humanistic" \\
\hline Surgeons & $28(21)$ & $31(23)$ \\
Hospital physicians & $20(13)$ & $38(26)$ \\
General practitioners & $5(4)$ & $35(27)$ \\
Psychiatrists & $2(4)$ & $16(31)$ \\
Women doctors & $5(11)$ & $7(16)$ \\
\hline
\end{tabular}

$\chi^{2}($ on $5 \times 5$ table of which this is an extract $)=30.62, \mathrm{df}=16, \mathrm{p}<0.02$

general practitioners and psychiatrists the least so. The greatest proportion of humanists was in the psychiatrist group, the smallest among the women doctors and the surgeons.

Table IV shows the self reported political views of the five groups of doctors. Surgeons were furthest to the right and psychiatrists furthest to the left; general practitioners and hospital physicians were in the middle, as were the women doctors.

\section{Discussion}

Information about British doctors' views of moral and ethical issues is sparse. ${ }^{2}$ These are often inferred from the pronouncements of professional organisations. The data provide some detail on the often stark corporate views that may be ascribed to the profession. Who would have thought, for instance, that in 1985 one quarter of any sample of doctors would disagree to some extent with the proposition that "tobacco sponsorship of any sport should be banned"? When it came to communication skills (in which we

TABLE IV—Self reported political views of doctors, by group. (Values are numbers (\%) of responses)

\begin{tabular}{lccc}
\hline \multicolumn{1}{c}{ Category of doctor } & Left of centre & Middle of the road & Right of centre \\
\hline Psychiatrists & $12(23)$ & $30(58)$ & $10(19)$ \\
General practitioners & $20(16)$ & $71(56)$ & $35(28)$ \\
Hospital physicians & $15(10)$ & $87(60)$ & $42(29)$ \\
Surgeons & $9(7)$ & $59(45)$ & $62(48)$ \\
Women doctors & $4(9)$ & $29(66)$ & $11(25)$ \\
\hline
\end{tabular}

Ten respondents did not answer this item.

$\chi^{2}=28 \cdot 41, \mathrm{df}=8, \mathrm{p}<0.001$ ourselves undertake teaching with medical students), the extent to which the need for improvement was apparently recognised by the profession surprised us.

The data may not precisely represent the views of "doctors" as a whole. Although in the groups of doctors surveyed the response rate was high, the study did not include several important specialistsfor example, obstetricians, pathologists, and anaesthetists-whose views may differ from those reported here. Nevertheless, our four specialist groups represent some $88 \%$ of all NHS career staff. ${ }^{3}$ Our study was of consultants and established general practitioners: it excluded young doctors, so their views are not known.

Yet opinions reported on moral issues are in substantial agreement with decisions made by the 1985 annual representative meeting of the British Medical Association. ${ }^{4}$ Four such matters covered by the questionnaire were discussed at the meetingtobacco sponsorship of sport, human embryo research, surrogate motherhood, and contraceptive advice for the under 16s. In each case the majority view at the BMA meeting was the same as we found in our study. What the questionnaire has done is to indicate, in addition, the distribution and strength of support and opposition.

On a practice issue, however-the desirability of some form of limited list in general practice-our respondents disagreed with the thrust of the vote at the BMA's 1985 meeting. It is difficult to summarise fairly the association's attitude towards a limited list, but, like President Coolidge reporting the preacher's attitude towards $\sin$, the association was against it. The annual meeting supported this approach and yet our respondents were very substantially in disagreement with it. It may be that the BMA delegate is "representative" with regard to moral issues but not with respect to matters relating to conditions of service. In any event, the resolutions of this meeting cannot be regarded as an invariably reliable guide to the views of senior members of major sections of the profession.

This study has shown few and insubstantial differences between specialty groups as regards doctors' attitudes to medicomoral and practice issues. Specialty groups differ substantially in both political outlook and medical philosophy, though, with women doctors seeming to occupy the middle ground on each of these dimensions. Surgeons (most right wing and technological) and psychiatrists (most left wing and humanistic) provide the greatest contrast. Monk and Thomas concluded, on the basis of the variables that they studied in the United States, that overall, psychiatrists tend to be at 


\section{Guiding consultants on private practice}

The Central Committee for Hospital Medical Services has emphasised how important it is for consultants to familiarise themselves with the contents of the new handbook on managing private practice in National Health Service hospitals. ${ }^{1}$ The committee will shortly issue guidance to all consultants, but some of the main points that will affect them are set out here.

\section{Identifying private patients}

A numbering system or similar mechanism must be set up so that except in emergencies no patient should proceed to investigation or treatment until his status has been identified. The consultant with primary responsibility for the patient should ensure that this is done for each private patient he admits.

A private patient is one who has given an undertaking to pay charges for accommodation and services; the patient's signature should be obtained and witnessed by the private patient officer, unless the consultants have agreed an alternative arrangement. The form should be in triplicate: one copy goes to the consultant, the second is retained by the administration, and the third is kept with the patient's notes. A doctor may not charge a fee unless the patient has given an undertaking to pay so it is in the consultant's interest to ascertain that the undertaking to pay form has been completed.

\section{Change of status}

The new guidance clarifies the legal position about patients changing from private to NHS status during their treatment. The Department of Health has confirmed that there can be no legal inhibition to a patient deciding to change to NHS treatment (or vice versa) once or repeatedly, though an outpatient may not be both private and NHS on the same visit to hospital. He may, however, return and seek NHS treatment on a subsequent visit. A patient who sees a consultant in private rooms is legally entitled to change his status and seek subsequent NHS treatment. A private inpatient may also change his status-for example, if he is found to be suffering from a different, more serious complaint from that for which he was admitted.

The guidance emphasises the six principles for treating private patients, which were agreed by the Joint Consultants Committee, the Central
Committee for Hospital Medical Services, and the government and published on 22 March (p 844).

\section{Section 58 of the NHS Act 1977}

The CCHMS has drawn attention to the emphasis that the Department has placed on the greater use of the provisions of section 58 of the NHS Act 1977 . This allows a health authority to contract with a third party to provide certain services and accommodation to people who are not private patients of the hospital. This would apply, for example, to the provision of pathology services to a local private hospital. The health authority must obtain the agreement of the doctors who would be affected by such an arrangement and it would be for the doctors to negotiate directly with the third party in respect of their professional fees, which would count as private practice earnings for the purposes of the $10 \%$ limit. It is probable that many health authorities will quite properly adopt such arrangements for work that may previously have been regarded as category II. The handbook lists other circumstances in which section 58 arrangements would be appropriate-for example, the processing of specimens from consultants private rooms, the NHS use of ambulances, the administrative costs of making records available, and for physiotherapists to see their own private patients outside their contracted hours.

Consultants should ensure that they are aware of any proposals for section 58 arrangements that may affect them.

\section{Collection of charges}

The CCHMS has discouraged consultants from acting as authorities' agents for collecting hospital charges. The new handbook outlaws the practice and states that health authorities should collect directly all fees due to a hospital.

\section{Release of health records}

The health records of an NHS patient are the property of the health authority concerned. Records may be borrowed for up to 24 hours by a consultant treating the patient privately with the consent of the patient and the NHS consultant. Stringent safeguards are required for the confidentiality and return of records issued in this way, and where photocopies instead of originals are supplied the health authority may make a charge.

\section{Authorisations}

Private practice may be carried out only in NHS hospitals that have been specifically authorised for the purpose by the Secretary of State. Separate authorisations are required for treating private inpatients and outpatients. Where authorisations for private inpatient treatment are concerned the guidance reiterates that the Secretary of State prefers authorisations expressed in terms of an annual number of bed days. The CCHMS has welcomed this advice as this system allows greater flexibility than the conventional limit on the number of private patients admitted at any one time.

1 Department of Health and Social Security. Health services management. Private practice in health service hospitals. London: DHSS, 1986.

\section{National Insurance contributions}

The BMA has revised its guidance note on National Insurance contributions to cover the year 1986-7. It has advice for employed and self employed doctors and is available only to BMA members, free of charge, from BMA regional offices. Members should quote their curren membership number and enclose a $\left(9^{\prime \prime} \times 6^{\prime \prime}\right)$ stamped addressed envelope.

\section{Managing information in NHS}

The government has published a strategic framework for information management in the hospita and community health services. The document is being issued as a draft to regional health authorities, special health authorities, and professional bodies for comment. This complements two initiatives that ministers have already taken, in agreemen with regional health authority chairmen, to improve information and its management in the hospital and community health services. In 1984 it was agreed that the reports of the Körner Steering Group on Health Services Information should be implemented by all health authorities - most of the recommendations by April 1987 and the remainder by April 1988. In 1985 it was agreed that the Körner Steering Group and the NHS Computer Policy Committee should be wound up and replaced by a single Information Advisory Group.

The framework proposes a devolved approach to the provision of information and information technology, with health authorities free to meet local and national needs in the way that suits them best. There will have to be adherence to internationally and nationally agreed standards for communications and the exchange of data between computers. This will ensure that the NHS information systems of the future will be compatible.

\section{Doctors' attitudes_continued from $p 1026$}

the opposite extreme from general surgeons while those going into internal medicine are more centrally located on most dimensions. Our data from a quite different context endorse these findings and may tend to confirm generally held beliefs about differences between these specialty groups.

We should like to thank the doctors who took part in the survey-some preliminary data from which were presented at the 1985 spring meeting of the Royal College of General Practitioners-and Messrs Upjohn (Medical Sciences Liaison) for assistance towards the cost of the study.

\section{References}

1 Harris CM. Medical stereotypes. Br Med f 1981:283:1676-7.

1a Brook P, Ingleby D, Wakeford RE. Students' attitudes to psychiatry: a study of first and final year clinical students' attitudes in six medical schools. Fournal of Psychiatric Education (in press) 2 Dunn JWN, Shaw RW. Medical ethics: a survey of general practitioners' attitudes. $\mathcal{J} R$ Coll Gen Pract 1983;33:763-7.

3 Anonymous. Medical and dental staffing prospects in the NHS for England and Wales, 1983. Health Trends 1984;16:25-9.

4 Anonymous. The week in Plymouth. BrMed $\mathcal{F} 1985 ; 291: 64-85$.

5 Monk MA, Thomas CB. Personal and social factors related to medical specialty practice. Johns Hopkins Medical fournal 1973;133:19.

(Accepted 7 March 1986) 